\title{
Lessons learned from launching the Manitoba Take-Home Naloxone Program
}

\author{
Songul Bozat-Emre, PhD (1,2); Shelley G. Marshall, MSc (3); Colin Zhong (1,4); Joss Reimer, MD (1,2,3)
}

Tweet this article

\begin{abstract}
The Government of Manitoba launched the provincial Take-Home Naloxone Program in January 2017. By the end of September 2017, there were over 60 sites operating in Manitoba. These sites distributed 765 kits to people at risk of opioid overdose, and 93 of these kits were replacement kits used in overdose events. Most of these events occurred among males $(60.2 \%)$ and in a private residence $(72.0 \%)$. Fentanyl and carfentanil were the most common substances reported during overdose events. Take-Home Naloxone Program data provide important information about the unique context of the opioid crisis in Manitoba.
\end{abstract}

Keywords: naloxone distribution, opioid, overdose response

\section{Introduction}

Harms associated with opioid overdose and misuse are a growing public health concern in Manitoba and in the other Canadian provinces. In Manitoba alone, the number of apparent opioid-related deaths increased by $87.5 \%$ from the first quarter of $2016(n=16)$ to the same period in $2017(n=30) .{ }^{1}$ Significant shifts have been noted in fentanyl-related deaths in 2017. Specifically, $40 \%$ of deaths $(n=12)$ were found to have the carfentanil analogue present. This provincial trend is of concern as carfentanil is considered 50 to 100 times stronger than fentanyl, with doses as small as one microgram causing toxic effects in humans. ${ }^{2}$

As a response to the emerging opioid crisis, the Street Connections program of the Winnipeg Regional Health Authority launched the first Take-Home Naloxone Program in Manitoba in January 2016. The key program components were adapted from the British Columbia Centre for Disease Control, Take-Home Naloxone Program, ${ }^{3}$ and further shaped by lessons learned through a qualitative consultation with people who use opioids in Winnipeg and other key stakeholders.

Manitoba Health, Seniors and Active Living (MHSAL) refined Winnipeg's pilot program and launched it as a provincial initiative in January 2017 as part of a public health opioid response plan. As part of the program, MHSAL provided take-home naloxone kits free of charge to persons at risk of opioid overdose, accompanied by training on overdose prevention, recognition and response, including the administration of naloxone. A summary of take-home naloxone kit components, distribution site criteria and a training manual are available online at www.gov.mb .ca/fentanyl/. An up-to-date list of take-home naloxone distribution sites in Manitoba is available at www.streetconnections.ca.

In this article, we present the key findings from the evaluation of the Manitoba TakeHome Naloxone Program from January 1 to September 30, 2017, as well as some of the key programmatic features that enabled the program's rapid expansion.

\section{Highlights}

- Take-Home Naloxone Programs should be designed to minimize the human resource burden involved with distribution, thereby facilitating access.

- Take-Home Naloxone Program indicators can provide important information about drug market dynamics and drug-related harms.

\section{Methods}

The Manitoba Take-Home Naloxone Program evaluation draws from three key sources of data. First, registered take-home naloxone distribution sites were opened into the inventory system created in Panorama (an electronic public health management system), providing information on the number of distribution sites and takehome naloxone kits delivered to sites from the provincial naloxone warehouse. Second, the Public Health Branch of MHSAL requires distribution sites to submit collated numbers on kits distributed to people at risk of opioid overdose (form available online at https://www.gov.mb .ca/health/publichealth/surveillance/docs /mhsu_6259_20171115.pdf).

Finally, when a lay responder uses a kit in an overdose event, the staff person replacing the kit completes and submits an overdose response form (available online at https://www.gov.mb.ca/health/publichealth /surveillance/docs/mhsu_6836_20161215 .pdf) as a requirement of program monitoring and evaluation. We conducted the 
data analysis using these three data sources for the period of January 1 to September 30, 2017.

\section{Results}

In Manitoba, there were nine distribution sites operating at the time of the launch of the provincial Take-Home Naloxone Program, and over 60 distribution sites operating by the end of September 2017, including in 24 First Nations communities. Between January 1 and September 30, 2017, the provincial naloxone warehouse delivered 1360 takehome naloxone kits to distribution sites in Manitoba. Take-home naloxone distribution sites provided 765 of these kits to people at risk of an opioid overdose. Of these 765 kits, 93 were replaced due to reported use during suspected opioid overdose events in the community. This suggests that for every eight kits distributed, one kit is used in relation to a suspected opioid overdose event.

A large proportion of the 93 suspected opioid overdose events (where take-home naloxone kits were used and replaced) occurred among people between the ages of 12 and $30(48.3 \%)$ (Table 1$)$. In addition, 56 were male, 30 were female and seven were of sex unknown/prefer not to say. Most of these overdose events occurred in the Winnipeg Health Region (79.6\%) and in a private residence $(72.0 \%)$. Blotter tabs of bootleg fentanyl (36.6\%) and carfentanil $(23.7 \%)$ were the most commonly reported drugs involved in suspected opioid overdose events where take-home naloxone kits were used.

In 49 of 93 reported overdose events $(52.6 \%)$, the lay responder did not call 911 (Table 2). The main reasons that 911 was not called included: "thought the person would get better on their own" (22.5\%), "worried police would come" (20.4\%) and "no phone" (14.3\%). Main actions taken by the lay responder in response to the overdose events included: "checked the person's breathing” (60.2\%) and "provided artificial respirations" (41.9\%). Furthermore, half of the females who overdosed received one dose $(0.4 \mathrm{mg})$ of naloxone, while males who overdosed most commonly received two doses $(0.8 \mathrm{mg})$ of naloxone (53.6\%) (data not shown).

\section{Discussion}

Manitoba successfully implemented the Take-Home Naloxone Program in a relatively

TABLE 1

Characteristics of suspected opioid overdose events where a take-home naloxone kit was reportedly used, Manitoba, January 1 to September 30, 2017, N = 93

\begin{tabular}{llc}
\multicolumn{1}{c}{ Characteristics } & \multicolumn{1}{c}{ Categories } & $\mathbf{n}(\%)$ \\
\hline Sex & Female & $30(32.3)$ \\
& Male & $56(60.2)$ \\
Age group (years) & Unknown/Prefer not to say & $7(7.5)$ \\
& $12-30$ & $45(48.3)$ \\
& $31-40$ & $23(24.7)$ \\
& 41 or over & $12(13.0)$ \\
Location of overdose event & Unknown/Prefer not to say & $13(14.0)$ \\
& Private residence & $67(72.0)$ \\
& Street & $7(7.5)$ \\
& Other $/$ Unknown/Prefer not to say & $19(20.5)$ \\
Health region of overdose event & Winnipeg & $74(79.6)$ \\
& Other health regions & $13(13.9)$ \\
& Out of province/Unknown/Prefer not to say & $6(6.5)$ \\
Substance type ${ }^{b}$ & Fentanyl & $34(36.6)$ \\
& Carfentanil & $22(23.7)$ \\
& Crystal meth & $13(14.0)$ \\
& Morphine & $9(9.7)$ \\
& Other substances ${ }^{c}$ & $15(16.0)$ \\
\hline
\end{tabular}

a Other locations include public washroom, hotel, shelter and in-vehicle.

${ }^{\mathrm{b}}$ Results are not mutually exclusive.

' Other substances include benzodiazepine, cocaine/crack, alcohol, codeine, methadone, heroin and dilaudid.

short period. The rapid expansion of Manitoba's Take-Home Naloxone Program is evident in the growth of distribution site numbers and reach, with sites in most health regions and over 24 First Nations communities within the first nine months of operation.

This success is attributable to several contextual and programmatic factors. First, pioneer take-home naloxone programs in other provinces, programs and regions have demonstrated the effectiveness of this intervention. ${ }^{4}$ This body of evidence has supported the expansion of take-home naloxone distribution in other jurisdictions, including Manitoba.

Second, the rescheduling of naloxone as a nonprescription medication by Health Canada $^{5}$ in 2016 enabled the Manitoba program to launch in 2017 with less restrictive distribution site criteria, as a prescribing practitioner was not required. Furthermore, the program offers overdose response training to anyone who wishes to become a trainer for lay overdose responders, which reduces the human resource burden on health care providers at distribution sites.

Finally, MHSAL established key partnerships before distribution site criteria were solidified to ensure that the program would be flexible enough to operate in various urban and remote settings. Consultations with the First Nations Inuit Health Branch and regional tribal councils were key in establishing a cost recovery agreement scheme. This has enabled First Nations and non-First Nations communities to gain similar access to take-home naloxone kits, promote standardized training across the province and establish the ability to collate and share naloxone distribution data consistent with the principles of First Nations ownership, control, access and possession. ${ }^{6}$

Our data highlight a continued reluctance of lay responders to call 911 in overdose events because of the fear of arrest or harm from police attendance. The Good Samaritan Drug Overdose Act was enacted into law in May 2017, providing immunity to arrest for simple drug possession to a person who 
TABLE 2

Characteristics of emergency response to suspected opioid overdose events where a take-home naloxone kit was reportedly used, Manitoba, January 1 to September 30, 2017,

$$
\mathbf{N}=93
$$

\begin{tabular}{|c|c|c|}
\hline Characteristics & Categories & n (\%) \\
\hline \multirow[t]{3}{*}{ Was 911 called? } & Yes & $34(36.6)$ \\
\hline & No & $49(52.6)$ \\
\hline & Unknown/Prefer not to say & $10(10.8)$ \\
\hline \multirow{5}{*}{$\begin{array}{l}\text { Reason(s) for NOT calling } \\
911^{\text {a }}\end{array}$} & No phone & $7(14.3)$ \\
\hline & Worried police would come & $10(20.4)$ \\
\hline & Thought the person would get better on their own & $11(22.5)$ \\
\hline & Other reasons $^{\mathrm{b}}$ & $6(12.2)$ \\
\hline & Unknown/Prefer not to say & $15(30.6)$ \\
\hline \multirow{13}{*}{$\begin{array}{l}\text { Action(s) taken during } \\
\text { overdose }^{\mathrm{a}}\end{array}$} & Stayed with the person until (s)he came around & $54(58.1)$ \\
\hline & Checked the person's breathing & $56(60.2)$ \\
\hline & Provided artificial respiration & $39(41.9)$ \\
\hline & Slapped or shook the person (not recommended) & $34(36.6)$ \\
\hline & Put the person in the recovery position & $25(26.9)$ \\
\hline & Checked the person's pulse & $32(34.4)$ \\
\hline & Yelled at the person & $39(41.9)$ \\
\hline & Provided chest compressions & $20(21.5)$ \\
\hline & Stayed with the person until first responders arrived & $28(30.1)$ \\
\hline & Checked the person's airway for obstruction & $20(21.5)$ \\
\hline & Gave the person a sternal rub & $30(32.3)$ \\
\hline & Other actions taken ${ }^{c}$ & - \\
\hline & Unknown & $17(18.3)$ \\
\hline \multirow{4}{*}{$\begin{array}{l}\text { Number of naloxone } \\
\text { doses }^{\text {d given }}\end{array}$} & One & $30(32.3)$ \\
\hline & Two & $40(43.0)$ \\
\hline & Three & $12(12.9)$ \\
\hline & Unknown & $11(11.8)$ \\
\hline
\end{tabular}

${ }^{\text {a }}$ Results are not mutually exclusive.

${ }^{\mathrm{b}}$ Other reasons include the person overdosed requesting not to call 911, taking the person to the emergency room themselves, and the person recovering quickly.

' Other actions taken during the overdose include putting the person in a cold shower and stimulating with ice.

${ }^{\mathrm{d}}$ One naloxone dose $=0.4 \mathrm{mg}$ (i.e. $0.4 \mathrm{mg} / \mathrm{mL}$ ).

- : Suppressed due to small sample size (i.e. $\mathbf{n}=1-5$ ).

calls 911 in an overdose emergency. Naloxone program data may be used to evaluate the impact of this policy change on the willingness of lay responders to call 911 during overdose events.

We found that blotter tabs of illicit fentanyl and carfentanil were the most commonly reported drugs involved in overdose events where take-home naloxone kits were reported to be used. To the best of our knowledge, the other urban centres in Canada have not reported this form of

\section{Conclusion}

Manitoba has successfully implemented the provincial Take-Home Naloxone Program in a relatively short period, providing opportunities to prevent opioid overdoses and reduce harms in emergency conditions. Data derived from the Take-Home Naloxone Program provide important information about the unique context of opioid use and related harms in Manitoba, enhance opioid surveillance reports and can inform other public health interventions. Naloxone distribution programs ultimately rely on the expertise of people with lived experiences and provide opportunities for meaningful engagement between health service providers and people at risk of an opioid overdose.

\section{Conflicts of interest}

The authors have no conflict of interest to declare.

\section{Authors' contributions and statement}

SBE interpreted the data, drafted and revised the paper; SM designed and conceptualized the work, analyzed and interpreted the data and drafted and revised the paper; $\mathrm{CZ}$ analyzed the data and revised the paper; and JR conceptualized the work and revised the paper.

The content and views expressed in this article are those of the authors and do not necessarily reflect those of the Government of Canada.

\section{References}

1. Government of Manitoba, Manitoba Health, Seniors and Active Living, Public Health and Primary Care Division, Epidemiology and Surveillance. Surveillance of opioid misuse and overdose in Manitoba: April 1 June 30, 2017. Winnipeg (MB): Government of Manitoba; 2017. Available from: http://www.gov.mb.ca /health/publichealth/surveillance /docs/q2_opioid.pdf

2. Raffa RB, Pergolizzi JV, LeQuang JA, Taylor R, Colucci S, Annabi MH. The fentanyl family: a distinguished medical history tainted by abuse. J Clin Pharm Ther. 2018;43(1):154-8. 
3. BC Centre for Disease Control. BC's Take Home Naloxone Program [Internet]. Vancouver (BC): BCCDC; 2012 [accessed 2017 Jan 12]. Available from: http://towardtheheart.com/ezine /3/take-home-naloxone-program

4. Clark AK, Wilder CM, Winstanley EL. A systematic review of community opioid overdose prevention and naloxone distribution programs. J Addict Med. 2014;8(3):153-63.

5. Health Canada. Notice: Prescription Drug List (PDL): Naloxone [Internet]. Ottawa (ON): Health Canada; [modified 2016 Mar 22, accessed 2017 Jan 12]. Available from: https://www .canada.ca/en/health-canada/services /drugs-health-products/drug-products /prescription-drug-list/notice-naloxone .html

6. First Nations Information Governance Centre. The First Nations Principles of OCAP $^{\circledR}$ [Internet]. Akwesasne (ON): FNIGC; [updated 2018; accessed 2017 Jan 12]. Available from: http:// fnigc.ca/ocapr.html 